Original Research Article

\title{
Does patellar tilt affect the outcome of total knee arthroplasty? a retrospective study
}

\author{
Gnanavel Chinnyyan, Sukesh A. Narayanan*, Appu Benny Thomas, Jacob Varughese
}

Department of Orthopaedics, VPS Lakeshore Hospital, Kochi, Kerala, India

Received: 29 April 2021

Accepted: 29 May 2021

\section{*Correspondence:}

Dr. Sukesh A. Narayanan,

E-mail: sukesh_an@yahoo.com

Copyright: (C) the author(s), publisher and licensee Medip Academy. This is an open-access article distributed under the terms of the Creative Commons Attribution Non-Commercial License, which permits unrestricted non-commercial use, distribution, and reproduction in any medium, provided the original work is properly cited.

\begin{abstract}
Background: Patellofemoral joint management during total knee replacement remains a controversial topic among knee surgeons. The purpose of this study is to evaluate the influence of resurfaced patellar component tilt on the functional outcome of total knee arthroplasty.

Methods: This is a retrospective study reviewing all the patients who underwent total knee arthroplasty in our institution, operated by a single surgeon using a single implant design.

Results: A total of 48 patients and 82 knees were enrolled into this study. Patients were evaluated by Oxford knee score, knee society score, Melbourne patellar score, anteroposterior, lateral, and Merchant's view radiographs. The patellar tilt was divided into three grades according the measurement obtained from knee radiographs.

Conclusions: A higher degree of patella tilt (more than 10 degree) is associated with poor outcome following total knee arthroplasty. Melbourne patella score is more sensitive than knee society score and Oxford score in assessing the effect of patella tilt on the outcome of total knee arthroplasty.
\end{abstract}

Keywords: Arthroplasty, Knee, Melbourne patella score, Patellar tilt

\section{INTRODUCTION}

Total knee arthroplasty (TKA) is the most commonly performed arthroplasty with very high success rate and satisfied patient outcomes. ${ }^{1}$ Anterior knee pain following TKA continues to be the Achilles heel, with a reported incidence of $7-25 \% .^{2,3}$ The decision regarding patella resurfacing is still a controversial chapter in TKA, with majority of the surgeons not in favour of resurfacing. ${ }^{4-7}$ Numerous studies have reported on potential complications like fracture and osteonecrosis with no statistical benefit from resurfacing the patella. ${ }^{8-10}$ While some routinely resurface the patella for better stair climbing, raising from a chair and also to avoid a later rescue procedure for persistent anterior knee pain. ${ }^{11,12}$

Another less understood aspect is the effect of the patellar tilt on the outcome of TKA. The patellar tilt following TKA depends on multiple factors like preoperative tilt, component rotation, size, thickness, design, and placement, including the patella resection angle. ${ }^{13}$ There are only very few published studies on the effect of patellar tilt to the outcome on TKAs with majority stating that patellar tilt does not affect the outcome of the TKA. ${ }^{14-17}$ The purpose of our study is to analyse whether the patellar tilt had any sort of influence on the clinical outcome of TKA.

\section{METHODS}

The present study is a retrospective analysis of 55 patients who underwent TKA in our department between January and December 2019, operated by a single surgeon and who had same implant (GENESIS $\diamond$ II-Smith and Nephew, USA). patient clinic. The study was conducted after ethical research committee approval from our hospital. Standard radiographs comprising of standing anteroposterior, true lateral radiograph in 30-degree flexion, Merchants view in 
45 degree of knee flexion were obtained to measure the parameters. The patellar tilt (Figure $1 \mathrm{~A}$ ) was measured as the angle between the equilateral axis of the patella and the prosthetic intercondylar line and was considered positive if tilted laterally and vice versa. ${ }^{18}$ The patellar component tilt (Figure $1 \mathrm{~B}$ ) was measured as the angle between the prosthetic intercondylar line and a line through the radiopaque marker in the patella. The difference between the two angles mentioned above is the resection angle. The patellar shift (Figure 1 C) was measured as the distance between middle of the prosthetic patella to a line drawn perpendicular to the prosthetic intercondylar line at its deepest point. ${ }^{17}$

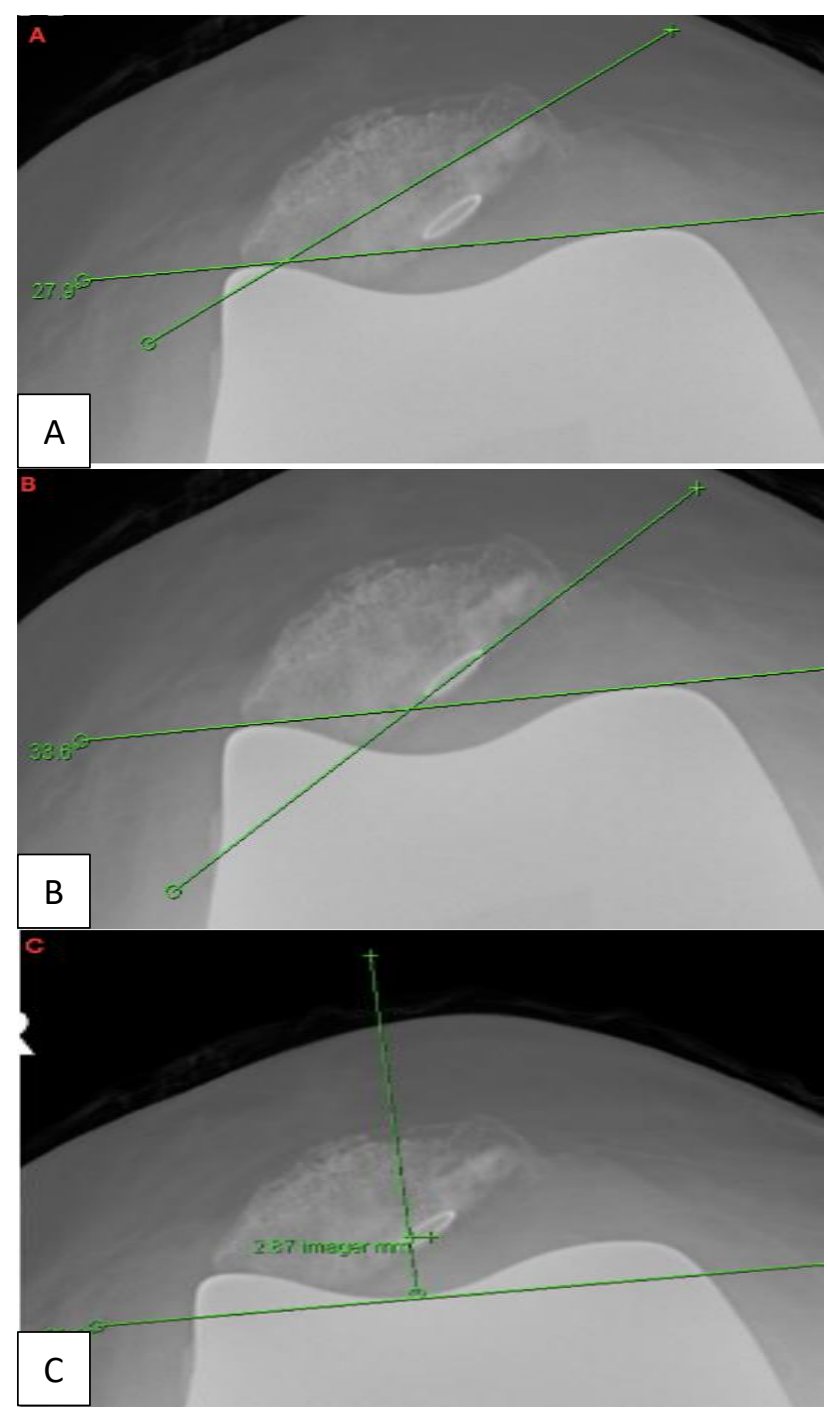

Figure 1: Merchant's view of knee. (A) Measuring the tilt of patella, (B) Measuring the tilt of resurfaced patella component and $(\mathrm{C})$ Measuring the patella shift.

All the TKAs were performed through the medial para patellar approach and a posterior stabilized knee design with 3 peg on lay dome shaped patella was used (GENESIS $\diamond$ II-Smith and nephew, USA). Patella resurfacing was done in all patients when the measured patella thickness was found to be above $19 \mathrm{~mm}$. The patella was resected to desired thickness using the patellar clamps provided by the manufacturer.

Of the 55 patients, 7 ( 3 had too small patella for resurfacing and 4 patients had incomplete data) were excluded from the study. For the final analysis 48 patients (82 knees) were available. Of the 48 patients, $43(90 \%)$ were females and $5(10 \%)$ were males. $34(71 \%)$ patients had bilateral knee replacements and 14 (29\%) had unilateral replacement. $39(81 \%)$ had primary knee osteoarthritis and $9(19 \%)$ had replacement due to inflammatory pathology. The average age at follow up was 64.5 years (range $41-83$ years). The average follow- up period was 24 months (range 13-32 months). 72 (87\%) knees had varus deformity and $10(13 \%)$ knees had valgus deformity preoperatively. $10(12.2 \%)$ knees needed lateral release to correct the residual patella tilt after the final implantation of knee components. The patellar tilt was divided into 3 grades, grade 1 ( -5 to 10 degrees), grade 2 (10.1-20 degrees), grade 3 (>20 degrees). Patients were evaluated using Oxford knee score (0-48 method-Dawson et al, knee society knee score Insall et al, and we included a patella specific score, the Melbourne patella score Feller et al as we were evaluating the influence of the patellar tilt on the clinical outcome in TKA. ${ }^{19,21}$ The scores were also graded into four as, excellent, good, fair and poor. Statistical analysis was performed by chi square test between excellent/good versus fair/poor outcomes and the mean, standard deviation and one-way analysis of variance were also calculated.

\section{RESULTS}

The mean age, average follow up period, range of movement, body mass index (BMI), patellar shift and Insall index for all the three grades of patellar tilt are tabulated in the Table 1 . The overall incidence of anterior knee pain was $30 \%$, the details are tabulated in Table 2. Of all the variables listed above only mean resection angle and patellar shift were statistically significant between the groups. The incidence of anterior knee pain was statistically significant between grade 1 and 2 and grade 1 and 3 but insignificant between grade 2 and 3 .

The mean, standard deviation and $\mathrm{p}$ value for all the three grades of the patellar tilt for the four scores: Oxford, KSSknee, KSS-functional, Melbourne patellar score were calculated (Table 3). Only Melbourne patellar score was statistically significant between three grades of tilt $(\mathrm{p}<0.05)$. The statistical analysis was calculated by chi square test and grading of the outcome done as excellent/good and fair/poor (Table 4). Again, the only score which was statistically significant to the patellar tilt between the three grades was Melbourne patellar score $(p<0.01)$. Then on further analysis of Melbourne patellar score between the groups using the chi square test and analysis of variance, we found a statistical difference between grade 1 and 2 and grade 1 and 3. There was no significant difference between grade 2 and 3 (Table 5). 
Table 1: Patient details.

\begin{tabular}{|lllllll|}
$\begin{array}{l}\text { Patellar tilt } \\
\text { (Mean) }\end{array}$ & $\begin{array}{l}\text { Mean age } \\
\text { (Year) }\end{array}$ & $\begin{array}{l}\text { Mean Follow- } \\
\text { up months }\end{array}$ & $\begin{array}{l}\text { Mean } \\
\text { ROM }\end{array}$ & BMI & $\begin{array}{l}\text { Patellar shift } \\
\text { (mm) }\end{array}$ & $\begin{array}{l}\text { Mean resection } \\
\text { angle (Degrees) }\end{array}$ \\
\hline Grade 1 (6.4) & 64.5 & 22.3 & 105 & 28.9 & 0.32 & 2.16 \\
\hline Grade 2 (15.7) & 63.7 & 22.6 & 109 & 29.1 & -2.7 & 5.36 \\
\hline Grade 3 (30.2) & 66.8 & 23.4 & 104 & 28.4 & -1.25 & 6.29 \\
\hline P value & 0.523 & 0.645 & 0.532 & 0.678 & 0.004 & 0.001 \\
\hline
\end{tabular}

Table 2: Incidence of anterior knee pain in post TKA patients with grades of patellar tilt.

\begin{tabular}{|lllllll|}
\hline Patellar tilt (Deg) & Knees-82 & No pain & Mild pain & Moderate pain & Severe pain & Total (\%) \\
\hline Grade 1 (-5-10) & $36(44)$ & 31 & 4 & 0 & 0 & $5(13.8)$ \\
\hline Grade 2 (10.1-20) & $22(27)$ & 12 & 9 & 1 & 0 & $10(45.5)$ \\
\hline Grade 3(>20) & $24(29)$ & 14 & 12 & 2 & 0 & $10(41.6)$ \\
\hline
\end{tabular}

Table 3: Assessment score.

\begin{tabular}{|c|c|c|c|c|}
\hline Score & Grade 1 & Grade 2 & Grade3 & P value \\
\hline \multirow{2}{*}{ Oxford } & Mean-37.8 & Mean-39.09 & Mean-36.91 & \multirow{2}{*}{$\mathrm{p}>0.05, \mathrm{p}=0.599$} \\
\hline & SD-6.74 & SD-6.74 & SD-8.44 & \\
\hline \multirow{2}{*}{ KSS-knee } & Mean-89.05 & Mean-90.04 & Mean-88.04 & \multirow{2}{*}{$\mathrm{p}>0.05, \mathrm{p}=0.536$} \\
\hline & SD-8.81 & SD-9.21 & SD-9.06 & \\
\hline \multirow{2}{*}{ KSS-functional } & Mean-78.61 & Mean-80.09 & Mean-74.35 & \multirow{2}{*}{$\mathrm{p}>0.05, \mathrm{p}=0.423$} \\
\hline & SD-18.95 & SD-11.08 & SD-18.66 & \\
\hline \multirow{2}{*}{$\begin{array}{l}\text { Melbourne } \\
\text { score }\end{array}$} & Mean-25.94 & Mean-24.18 & Mean-23.41 & \multirow{2}{*}{$\mathrm{p}<0.05, \mathrm{p}=0.011$} \\
\hline & SD-2.97 & SD-2.82 & SD- 3.96 & \\
\hline
\end{tabular}

Table 4: Detail of statistical analysis of scores.

\begin{tabular}{|c|c|c|c|}
\hline Scores & $\begin{array}{l}\text { Excellent/ } \\
\text { Good } \\
\text { outcome }\end{array}$ & $\begin{array}{l}\text { Fair/ } \\
\text { Poor } \\
\text { outcome }\end{array}$ & $P$ value \\
\hline \multicolumn{4}{|c|}{ Oxford score } \\
\hline Grade $1-36$ & 32 & 4 & \multirow{3}{*}{$\begin{array}{l}\mathrm{p}>0.05 \\
\mathrm{p}=0.709\end{array}$} \\
\hline Grade $2-22$ & 20 & 2 & \\
\hline Grade 3-24 & 20 & 4 & \\
\hline \multicolumn{4}{|l|}{ KSS-knee } \\
\hline Grade $1-36$ & 34 & 2 & \multirow{3}{*}{$\begin{array}{l}p>0.05 \\
p=0.753\end{array}$} \\
\hline Grade $2-22$ & 21 & 1 & \\
\hline Grade 3-24 & 21 & 3 & \\
\hline \multicolumn{4}{|c|}{ KSS-functional } \\
\hline Grade 1-36 & 29 & 7 & \multirow{3}{*}{$\begin{array}{l}\mathrm{p}>0.05 \\
\mathrm{p}=0.420\end{array}$} \\
\hline Grade2 -22 & 20 & 2 & \\
\hline Grade 3-24 & 17 & 7 & \\
\hline \multicolumn{4}{|c|}{ Melbourne score } \\
\hline Grade $1-36$ & 31 & 5 & \multirow{3}{*}{$\begin{array}{l}\mathrm{p}<0.01 \\
\mathrm{p}=0.0075\end{array}$} \\
\hline Grade $2-22$ & 11 & 11 & \\
\hline Grade 3-24 & 14 & 10 & \\
\hline
\end{tabular}

Table 5: Study specific Melbourne patella score.

\begin{tabular}{|lll|} 
Grades & $\begin{array}{l}\text { P value, Chi } \\
\text { square }\end{array}$ & $\begin{array}{l}\text { P analysis of } \\
\text { variance }\end{array}$ \\
\hline $\begin{array}{l}\text { Grade 1 vs. } \\
\text { Grade 2 }\end{array}$ & $\begin{array}{l}\mathrm{p}<0.01, \\
(\mathrm{p}=0.0028)\end{array}$ & $\mathrm{p}<0.05,(\mathrm{p}=0.030)$ \\
\hline $\begin{array}{l}\text { Grade 1 vs. } \\
\text { Grade 3 }\end{array}$ & $\mathrm{p}<0.05,(\mathrm{p}=0.014)$ & $\mathrm{p}<0.01,(\mathrm{p}=0.007)$ \\
\hline $\begin{array}{l}\text { Grade 2 vs. } \\
\text { Grade } 3\end{array}$ & $\mathrm{p}>0.05,(\mathrm{p}=0.57)$ & $\mathrm{p}>0.05,(\mathrm{p}=0.459)$ \\
\hline
\end{tabular}

\section{DISCUSSION}

There are few published studies reporting the influence of patellar tilt to the clinical outcome of TKAs. Our present study was conceived after observing a very high degree of patellar tilt in our patients and only few had significant complaint. The incidence of any anterior knee pain including mild pain in our study is $30 \%$, which is very high compared to the reported incidence of anterior knee pain of $7-16 \%$ in resurfaced patella in published metaanalysis. ${ }^{2,3}$

The mean tilt in our study was 16.3 degrees ( -2 to 50 degrees) which is very high, when compared to the recommended normal $(-5$ to +5 degree) patellar tilt post TKA. ${ }^{17}$ Pellengahr et al, Jung et al, and Morteza et al, have reported that patellar tilt is not associated with poor clinical outcome, but their mean patellar tilt was less than 10 degrees which corresponds to the grade 1 in our study. ${ }^{15-17}$ On the other hand, Bindelglass et al have reported a larger tilt and higher percentage of tilt, but have not used patellar specific score in their study nor graded the patellar tilt to find out does any grade of the tilt correlates with anterior knee pain. ${ }^{14}$ To our best of knowledge, no study has graded the patellar tilt and used Melbourne patellar score to predict the outcome of the patellar tilt in TKA. In our study the patellar tilt more than 10 degrees was associated with increased anterior knee pain and was statistically significant and it correlated well with Melbourne patellar score. If patient has patellar tilt of $>10$ degrees he has a $50 \%$ chance of having anterior knee pain and if the tilt was 
$<10$ degrees, the chance of having anterior knee pain was only $10 \%$.

We believe that the major cause of increase in the mean tilt in our series is the high patella resection angle which is statistically significant between grade 1 and grade 2/3 (Table 4 and 5). The same has been reported by Kim et al in a retrospective study on 56 patients (76 knees) who underwent TKA. ${ }^{22}$ A complete tension free eversion of patella is essential to correctly place the patellar clamp for resection. In cases of tight knee, an essential step would be performing a lateral release before the patellar resection rather than doing it after the patellar implantation. The use of a simple bull's eye spirit level on the patella clamp will be an added benefit to the surgeons. ${ }^{23}$

Patellar shift, even though it was statistically significant between the groups but was not correlating with anterior knee pain and Melbourne patellar score. This may be due to the effect of the tilt rather than the cause of the tilt, as grade 2 has more shift than grade 3 tilt (Table 3 ) and further studies will be needed to confirm this.

Our study was retrospective, with short follow up period and possibly uncorrected variables between the groups. We have not used multivariate analysis as these might have influenced the results. A large randomized controlled study is needed to confirm or disapprove our observations.

The main conclusion and significance of our study is that even with very high mean patellar tilt and higher incidence of anterior knee pain as in our case series, the most commonly used scores such as Oxford knee score and both parts of knee society knee score were not able to show the statistically significant difference in outcome between the grades of patellar tilt. Melbourne patellar score was able to differentiate it and predict poor outcome in TKAs with higher degree of patellar tilt.

\section{CONCLUSION}

To conclude, a patellar tilt of more than 10 degrees may be associated with poor outcome in TKAs and we highly recommend the use a patella specific score to predict the outcome in all future studies investigating the evercontroversial patella resurfacing in TKAs.

\section{Funding: No funding sources}

Conflict of interest: None declared

Ethical approval: The study was approved by the institutional ethics committee

\section{REFERENCES}

1. Robertson O, Dunbar M, Pehrsson T, Knutson K, Lidgren L. Patient satisfaction after knee Arthroplasty-A report on 27,372 knees operated on between 1981 and 1995 in Sweden. Acta Orthop Scand. 2000;71(3):262-7.
2. He JY, Jiang LS, Dai LY. Is patellar resurfacing superior than non-resurfacing in total knee arthroplasty? A meta-analysis of randomized trials. Knee. 2011;18(3):137-44.

3. Pilling RW, Moulder E, Allgar V, Messner J, Sun Z, Mohsen A. Patellar resurfacing in primary total knee arthroplasty J Bone Joint Surg Am. 2012;94(24):2270-8.

4. Feller JA, Bartlett RJ, Lang DM. Patellar resurfacing versus retention in total knee arthroplasty. J Bone Joint Surg Br. 1996;78:226-8.

5. Waters TS, Bentley G. Patellar resurfacing in total knee arthroplasty. A prospective, randomized study. J Bone Joint Surg Am. 2003; 85:212-7.

6. Clements WJ, Miller L, Whitehouse SL, Gravels SL, Ryan P, Crawford RW. A report from the Australian Orthopaedic Association National Joint Replacement Registry. Acta Orthopaedica. 2010;81(1):108-13.

7. Robertsson O, Lidgren L, Sundberg M, Dahl AW. Swedish knee Arthroplasty register annual report 2012. 2018.

8. Grace JN, Sim FH. Fracture of the patella after total knee arthroplasty. Clin Orthop Relat Res. 1988;230:168-75.

9. Boyd AD Jr, Ewald FC, Thomas WH, Poss. R, Sledge CB. Long-term complications after total knee arthroplasty with or without resurfacing of the patella. J Bone Joint Surg Am. 1993;75:674-81.

10. Pavlou G, Meyer C, Leonidou A, As-Sultany M, West $\mathrm{R}$, Tsiridis E. Patellar resurfacing in total knee arthroplasty: does design matter? A meta-analysis of 7075 cases. J Bone Joint Surg Am. 2011;93(14):13019.

11. Schroeder-Boersch H, Scheller G, Fischer J, Jani L. Advantages of patellar resurfacing in total knee arthroplasty. Two-year results of a prospective randomized study. Arch Orthop Trauma Surg. 1998;117:73-8.

12. Newman JH, Ackroyd CE, Shah NA, Karachalios T. Should the patella be resurfaced during total knee replacement? Knee. 2000;7:17-23.

13. Eisenhuth SA, Saleh KJ, Cui Q. Patellofemoral instability after total knee arthroplasty. Clin Orthop Relat Res. 2006;446:149-60.

14. Bindelglass DF, Cohen JL, Dorr LD, Patellar tilt and subluxation in total knee Arthroplasty. Relationship to pain, fixation, and design. Clin Orthop Relat Res. 1993;286:103-9.

15. Pellengahr C, Maier M, Müller PE, Dürr HR, Schulz $\mathrm{C}$, Zysk $\mathrm{S}$ et al. Surgical and Anatomic Parameters Influencing Femoro patellar Pain in Total Knee Arthroplasty. Eur J Trauma. 2002;28(4):242-6.

16. Jung JW, Cheon SH, Kyung HS. The Correlation of Postoperative Femoral Component Rotation Angle and Patella Tilt Angle with Clinical Results in Total Knee Arthroplasty. J Korean Knee Soc. 2011;23(2):96-103.

17. Meftah M, Jhurani A, Bhat JA, Ranawat AS, Ranawat CS. The Effect of Patellar Replacement Technique on 
Patellofemoral Complications an Anterior Knee Pain. J Arthroplasty. 2012;27:6.

18. Dawson J, Fitzpatrick R, Murray D, Carr A. Questionnaire on the perceptions of patients about total knee replacement. J Bone Joint Surg Br. 1998;80(1):63-9.

19. Insall JN, Dorr LD, Scott RD, Scott WN. Rationale of the Knee Society clinical rating system. Clin Orthop Relat Res. 1989;248:13-4.

20. Feller JA, Bartlett RJ, Lang Dm. Patellar resurfacing versus retention in total knee Arthroplasty. J Bone Joint Surg. 1996;78-B:226-8.

21. Chia SL, Merican Am, Devadasan B, Strachan RK, Amis AA. Radiographic features predictive of patellar malt racking during total knee arthroplasty. Knee Surg Sports Traumatol Arthrosc. 2009;17:1217-24.
22. Kim JH, Yoo BW, Kim CW. Influence of the Rotational Alignment of the Femoral and Patellar Components on Patellar Tilt in Total Knee Arthroplasty. Knee Surg Relat Res. 2015;27(3):1637.

23. Pongkunakorn A, Palawong P, Chatmaitri S, Phetpangnga N. Use of a digital protractor and a spirit level to determine the intraoperative anteversion of femoral component during cemented hip hemiarthroplasty: a prospective clinical trial. Arch Bone Joint Surg. 2019;7(4):314.

Cite this article as: Chinnyyan G, Narayanan SA, Thomas AB, Varughese J. Does patellar tilt affect the outcome of total knee arthroplasty? a retrospective study. Int J Res Orthop 2021;7:806-10. 